\title{
O humor na novela de suspense Sangue fresco, de João Carlos Marinho*
}

\author{
Márcia Maria de Melo Araújo** \\ Maria Zaira TurChI ${ }^{* * *}$
}

\begin{abstract}
Resumo
Compreender o humor e refletir sobre ele na novela de suspense Sangue fresco, de João Carlos Marinho, é a proposta deste trabalho, cujos objetivos são ressaltar a importância do gênero policial de suspense na produção literária juvenil e demonstrar como o autor trabalha o humor por meio da paródia e da hipérbole, construindo uma crítica social com criatividade e irreverência, parodiando o gênero policial com magia e encantamento.
\end{abstract}

PALAVRAS-CHAVE: literatura juvenil, suspense, violência, caricatura, humor, riso.

The humor in the suspense novel Fresh blood, by João Carlos Marinho

\section{AbSTRACT}

Understanding the humor and reflecting upon it in the suspense novel Fresh blood, by João Carlos Marinho, is the proposal of this article, which objectives are to stand out the importance of the police suspense gender in the youthful literary production and to demonstrate how the author works the humor through parody and hyperbole, constructing a kind of social criticism with creativity and irreverency, parodying the police gender with magic and enchantment.

KEY WORDS: juvenile literature, suspense, violence, caricature, humor, laughing.

Até recentemente, as narrativas de mistério e suspense têm segurado um público ávido pelo inusitado e pelo enigmático. É o que acontece com a novela de suspense de João Carlos Marinho, autor de histórias de romance policial para crianças e jovens, em que trabalha a paródia a esses tipos de romances de forma irônica, irreverente e bem-humorada.

* Sob o mesmo título, este artigo é síntese do Trabalho de Conclusão de Curso apresentado ao Departamento de Estudos Lingüísticos e Literários da Faculdade de Letras da Universidade Federal de Goiás.

** Mestranda em Estudos Literários pela Faculdade de Letras da Universidade Federal de Goiás. E-mail: marcimelo@gmail.com

*** Doutora em Teoria da Literatura pela Pontifícia Universidade Católica do Rio Grande do Sul. E-mail: zaira@letras.ufg.br 
Neste artigo, investigaremos como o autor constrói o humor em Sangue fresco, partindo do pressuposto de que as narrativas de mistério e suspense, projetadas sobre a ocorrência de crimes e alinhadas a protagonistas detetives, despertam a atenção do público, principalmente o infantojuvenil, há muito tempo.

Como inovação da história policial, permeada pela ironia e non sense, João Carlos Marinho incorpora e parodia os elementos mais tradicionais do gênero. O gênio do crime (Marinho, 1969) apresenta uma sátira na caricatura do detetive norte-americano que, paralelamente a Gordo e seus amigos, pretende descobrir a fábrica clandestina que falsifica figurinhas de futebol. $O$ caneco de prata (Marinho, 1971) afeta o mundo das crianças com o mistério na disputa de um campeonato de futebol entre escolas de São Paulo, cujo prêmio, um caneco de prata, leva o diretor de uma das escolas a lançar mão de todos os expedientes para garantir a vitória de seus jogadores. Em Sangue fresco (Marinho, 1986), uma quadrilha internacional liderada por um norteamericano faz contrabando de sangue de crianças, cuja idade varia de 9 a 11 anos. Elas são seqüestradas e presas em um curral escondido na selva amazônica, o que aumenta o risco e a aventura da turma do Gordo.

Segundo Lajolo e Zilberman (1985, p. 141), desde sua primeira obra, o estilo de João Carlos Marinho se define pelo acúmulo dos detalhes de violência ou pela forma, ora natural ora exagerada, de narrar as açôes, promovendo um discurso crítico que se perfaz pela ironia e pelo riso. As autoras explicam:

A forma pela qual o texto desse autor envereda por uma representação crítica do real é muito sutil e rigorosamente literária: por via da redundância vertiginosa e agressiva dos detalhes da violência ou, paradoxalmente, na naturalidade de registro de açóes e instrumentos mirabolantes, ou ainda na sucessão de apelos a recursos sofisticados da técnica, seus livros ferem a nota crítica (Lajolo e Zilberman, 1985, p. 142).

A ficção científica e o mistério policial na literatura infantil e juvenil brasileira dos anos 70 não vão encontrar similar na literatura não-infantil, de pobre tradição nessa área. Ainda de acordo com as autoras, o que identifica certos livros policiais e de ficção científica como infantis é a presença de crianças no papel de detetives ou beneficiários dos poderes oferecidos pela tecnologia científica. Além disso, o ambiente de violência e corrupção visto em livros congêneres para adultos e a fundamentação científica 
e digressão filosófica são substituídos ou diluídos para o público infantil, seguindo assim estereótipos como o do pesquisador maluco ou de viajantes extraterrestres.

Turchi (1995, p. 132) frisa que João Carlos Marinho sabe construir, "com humor e ironia, personagens vivas e dinâmicas, muitas delas verdadeira paródia a personagens dos romances de enigma e dos romances negros". Aliás, este é um dos critérios para enquadrar a obra de Marinho como de suspense: ela surge a partir da combinação do romance de enigma e do romance negro. Para afirmar isto, seguimos a tipologia de Todorov (1970), na qual distinguimos os três tipos de narrativas policiais: o romance de enigma, que cria uma atmosfera de curiosidade no leitor por meio dos procedimentos do investigador para elucidar o crime; o romance negro, que traz a ação e o perigo mais para o presente, superpondo duas histórias (a história do crime e a história do desvendamento do crime) e adensando a atmosfera para o suspense, e, por último, o romance de suspense.

Esse último tipo surge numa época de transição entre o romance de enigma e o romance negro, coexistindo por algum tempo com este último. Para Todorov (1970), no plano histórico, o romance de suspense apareceu em dois momentos, dando origem assim a dois subtipos de romance de suspense. O primeiro, Todorov o chama de "História do detetive vulnerável”, no qual ele perde a imunidade, é espancado, e vive em perigo constante, o que o torna integrado no universo das demais personagens, em vez de apenas atuar independentemente como observador. $\mathrm{O}$ segundo subtipo de romance denomina-se, segundo Todorov, a "História do suspeito-detetive". Narra-se um crime cometido logo no início da história e as suspeitas indicam uma pessoa que terá que provar sua inocência. Para isso ela deverá encontrar o verdadeiro culpado. Bem ao estilo de alguns filmes modernos.

De acordo com Turchi (1995, p. 135), o relacionamento de Berenice e Gordo é característica do romance negro presente no romance de suspense de João Carlos Marinho como herança daquele, pois nos romances da série negra há lugar para paixões e ódios, diferentemente dos romances de enigma em que a atuação do detetive não cede lugar para o amor. Reunimos, também, exemplos que delimitam os romances de enigma, como a presença de um grupo de garotos na qualidade de detetives e a presença de um culpado que mata por questões pessoais e não é o detetive. Desta maneira, podemos notar que essa novela está diluída entre o romance de enigma e o de série negra, formando assim o romance de suspense. 


\section{DA VIOLÊNCIA AO RISO}

Para análise do humor em Sangue fresco, é necessário recorrer à tipologia do romance policial, em que Todorov (1970) faz distinção entre dois eixos narrativos: a história do passado e a do presente. Segundo o autor, o romance de enigma superpóe dois planos narrativos: primeiro, traz a história do crime (passado); segundo, a do inquérito (presente). Nota-se nesses tipos de narrativas que a primeira história para parecer mais verossímil possível irá tratar da história do crime, mostrando-a ao leitor sem revelar o assassino. A segunda, mostra um lento aprendizado, em que o detetive tentará reconstruir um acontecimento passado, reunindo pistas, culminando com a descoberta do crime e do culpado.

No romance negro, as duas histórias se superpõem, trazendo a ação e o perigo para o presente. A partir da combinação do romance de enigma e do romance negro surge um terceiro tipo chamado romance de suspense, o qual conserva do primeiro romance o mistério e as duas histórias (do passado e do presente), e do segundo, a história do presente que tomará o lugar central. João Carlos constrói a narrativa in media res, ou seja, a história está em andamento com algumas crianças seqüestradas sendo levadas de avião para o meio de uma floresta, quando a narração tem início.

O segundo capítulo mostra como as crianças deveriam obedecer aos seqüestradores, sob o perigo de serem castigadas com a pena de morte. Ricardinho desobedece e é colocado dentro de uma gaiola com barras de ferro entrelaçada de fios de arame grosso. Uma sucuri esmaga-o e o engole. Ele serve de exemplo às demais crianças e às recém-chegadas. A partir desse capítulo, podemos comentar o tratamento que João Carlos Marinho dispensa às cenas de violência. É o que Silva (1995) considera de saída sui generis. $\mathrm{O}$ autor descreve essas cenas em ritmo de câmara lenta e em tom casual, sem emoção, e o efeito é o traço caricatural, presente em Sangue fresco não de forma isolada:

A sucuri meneou, fez que sim, fez que não, e deu o bote.

[...]

As crianças estavam pasmas, umas tremiam que nem geléia, outras queriam atacar e libertar Ricardinho, mas um medo estranho, naquele lugar estranho, as paralisou.

A sucuri esmagou o crânio de Ricardinho e, depois que o menino virou pasta, ela foi soltando baba lubrificante sobre ele, a baba escorrendo da 
boca horrenda, às vezes parava um pouco e esticava o pescoço, em seguida babava de novo: quando Ricardinho estava bem babado, a sucuri engoliu tudo, em espasmos, a gente via o diâmetro dela estufar.

Ficaram de fora da boca os pés de Ricardinho calçando os dois tênis verticais e paralelos como se o menino estivesse dormindo num vagão leito. A sucuri se alongou e dormiu (Marinho, 1986, p. 12-13 - Ao longo da exposição, a obra analisada será indicada apenas pelo número das páginas).

No terceiro capítulo, Nadia, Paulo e Simone (recém-chegados) começam a entender o que vai acontecer com eles: serão doadores involuntários de sangue. O sangue contrabandeado é levado de avião para um destino desconhecido. Até aqui o que se percebe é que a narrativa segue um tempo presente e que os garotos estão expostos ao perigo, pois foram seqüestrados. Isto nos faz lembrar Todorov (1970) que, ao estabelecer uma tipologia do romance policial, nos alerta para a existência de duas narrativas que se combinam: a história do crime (ausente, mas real) e a história do desvendamento desse crime (presente, porém insignificante por não existir "em si”, mas em função de um determinado crime).

No quarto capítulo, o autor faz um flashback, ou seja, uma volta ao passado, para contar como surgiu a organização chamada Fresh Blood Corporation, cujo fundador é Ship O'Connors, norte-americano nascido em Chicago, formado em medicina e especialista em doenças de sangue. Sócio de Schsnels, Ship tem um consultório e sonha ser milionário, o que provavelmente não iria acontecer se ele continuasse atendendo a clientela pobre e pequena que freqüentava o consultório. Mas, por acaso, Schsnels faz uma transfusão de sangue em um homem que não tinha cura, o sangue doado era do filho do doente, um garoto de dez anos. Depois da transfusão, como num passe de mágica, o homem recupera a saúde.

Schsnels e Ship realizam outras experiências e descobrem que o sangue de crianças entre nove e onze anos curava todas as doenças. Ship não quer contar a descoberta à comunidade científica para poder ficar milionário, só que o seu sócio decide o contrário e é assassinado por isso. $\mathrm{O}$ próprio Ship se encarrega de matá-lo e oculta o cadáver, enterrando-o em um matagal. Mas Ship encontra outra barreira: em todos os países há uma lei que proíbe a doação de sangue por crianças. Para burlá-la, ele resolve formar um curral escondido e enviar para lá crianças bem nutridas. Ship escolhe a floresta amazônica como local privilegiado para o seu crime e São Paulo como fonte de matéria-prima, ou seja, ele seqüestra as crianças em 
São Paulo e as envia para a floresta amazônica, onde elas não podem ser encontradas.

Para não levantar suspeitas, Ship funda a Fresh Blood Corporation com empréstimo de um banqueiro suíço e colaboração de dois sócios, um alemão e um japonês. Abrimos parêntese para mostrar essa interessante combinação: um americano, um alemão e um japonês, ressaltando que a Alemanha e o Japão foram países cenários de horror. $\mathrm{O}$ autor reforça a imagem de mau de Ship O’Connors através da menção a esses países pois, se na Alemanha houve Hitler, no Japão houve, depois do episódio de Pearl Harbor, o lançamento da bomba atômica em Hiroshima e Nagasaki. Ship irá se moldar nisso para construir o lugar onde as crianças ficarão reclusas e a perseguição aos garotos chefiados pelo Gordo terá uma cena bem próxima da que aconteceu no Japão, só que com bombas de Napalm.

A Fresh Blood abre vários bancos de sangue autorizados por lei, em São Paulo e em diversas cidades, onde recebia sangue de pessoas do povo, doado ou vendido, e mandava-o para o exterior de navio. No caminho, o sangue era jogado fora e substituído pelo sangue das crianças seqüestradas. Diante das autoridades, Ship exportava sangue legal e fazia milagres, curando todos de tudo.

Este é basicamente o resumo da segunda história para o leitor, embora represente a primeira história, a do passado (ausente, mas real), se se levar em conta que é a partir dela que os garotos serão seqüestrados. Deste modo, ao escrever Sangue fresco, nosso autor consegue, pelo caráter fabular das narrativas, construir um mundo verossímil. Os elementos de verossimilhança estão presentes ao lado da alogicidade, quando presenciamos cenas vividas em São Paulo ou no interior da selva amazônica, contrastando com as aventuras vividas por crianças de idade entre 9 e 11 anos, que doam sangue semanalmente. $\mathrm{Na}$ realidade, sabemos que um doador de sangue só pode doar de dois em dois meses se for homem, e de três em três meses se for mulher.

Lajolo e Zilberman (1985) confirmam que a naturalidade com que narrador e personagens enunciam os exageros de violência e se referem aos mais sofisticados artefatos da tecnologia soma-se ao non sense com que certas conseqüências se engastam umas nas outras. Como exemplos, podemos citar a morte de Ricardinho no início do romance ou o satélite espiāo de Cabo Kennedy no valor de quinze milhões de dólares. 
O engraçado não é a cena grotesca da sucuri engolindo Ricardinho, mas como os pés de Ricardinho ficam do lado de fora da boca da sucuri; o satélite espião, que mais parece um cão farejador-robô, explode ao cheirar o chulé do tênis do Gordo e Cabo Kennedy é uma pessoa e não o local de onde a Nasa envia satélites nos EUA. Essa ambigüidade rompe a seriedade e provoca o riso. Tudo isso confere ao texto um traço de humor e modernidade e permite que João Carlos Marinho inove esteticamente em um gênero de perfil tão marcado quanto o livro policial.

Fator imprescindível neste estudo e que consideramos como traço característico de João Carlos Marinho e de inovação nas histórias de suspense é a presença do riso. $\mathrm{O}$ padrão das histórias policiais, que não têm humor via de regra, é subvertido no texto de João Carlos Marinho por meio da paródia e da hipérbole, resultando na caricatura e no grotesco.

A caricatura da figura materna está bem explícita no episódio das mães reunidas no Salão de Convenções do Anhembi. Ao discutirem a redação de um manifesto a ser enviado ao governo, exigindo a proteção das crianças paulistas e a prisão dos seqüestradores, as mães se assemelham a um bando de periquitos na mangueira. Vejamos o seguinte trecho:

A mãe do Biquinha achava que devia escrever assim, a mãe do Godofredo opinava que o manifesto devia ser agressivo, a mãe dum outro achava que tinha que ser moderado, uma outra mãe achava que não devia chamar o presidente da república de Vossa Excelência, a mãe da Sílvia dizia que o manifesto tinha que ser curto, a mãe da Mariazinha falou que tinha que ser longo, atacando o governo, uma mãe disse que aquela reunião era coisa de comunista, uma mãe que tivera quatro filhos raptados chorava, apesar de reconhecer que com aquilo estava fazendo muita economia, e os quatro viviam dando patada um no outro, com o que a casa acalmara, agora podia escolher $o$ programa de televisão que ela preferia, que detestava criança, mas pariu, pariu, tem que gostar, por isso, chorava, a redação do manifesto continuava, todas querendo olhar por cima do ombro da que escrevia (p. 44, grifo nosso).

Podemos, a partir desse excerto, visualizar a figura de mãe que não é o estereótipo de rainha do lar, mas de uma pessoa que percebe que o mundo à sua volta, sem a presença dos filhos, pode ser melhor. Ao lutarem por seus direitos, as mães revelam também um lado diferente do que normalmente se espera da figura da mãe ordeira e doce. Cada uma quer manifestar sua opinião e o manifesto vira bagunça. 
Portanto, a caricatura, em Sangue fresco, é apresentada sob a forma do exagero e do ridículo. $\mathrm{O}$ exagero pode ser verificado em muitas passagens do romance, mas retomemos o episódio do manifesto das mães. Trata-se de quarenta mil mães reunidas no Anhembi, enfrentando o batalhão de choque:

Vocês sabem, vocês já viram, reunião de pais e mestres, com duas mães presentes, ninguém agüenta, imagine aquela, com quarenta mil - o desgraçado que inventou a Reunião de Pais e Mestres deu uma contribuição inestimável para a discórdia humana; das ofensas passaram às bolsadas, uma mãe dando bolsada na outra, o Shopping Center Iguatemi instalou uma barraca para ir vendendo bolsas. Quando uma mãe esfrangalhava a sua bolsa na cabeça de outra, ia na barraca, assinava um Cheque especial Banespa, comprava outra bolsa e voltava para a batalha.

Depredaram o Palácio das Convençôes do Anhembi.

A Central de Polícia mandou um batalhão de choque, acostumado a enfrentar terrorista, acontece que mãe brava é muito pior, o batalhão de choque levou uma surra das mães, as bombas de gás lacrimogênio e as bombas de efeito moral adiantaram nada (p. 44-45).

O exagero também pode ser visto nesta passagem, quando a sucuri tenta dar o bote no Gordo enquanto ele tomava banho e estava ensaboado:

A sucuri se enrolou no peito do Gordo, excitada, amada-amante, preparou o apertão quebra-costela, concentrou os poderosos músculos e deu um quebra-costela de luxo, daria para esmagar um hipopótamo.

Acontece que o peito do Gordo estava ensaboado, no que a sucuri apertou, ela escorregou em volta, quanto mais apertava, mais o sabão a fazia rodopiar, ela ficava com raiva e apertava mais, e, abraçando mais escorregava em dobro.

O Gordo, que estava de olho fechado, lavando a cara, ao receber o bote, não entendia nada, a cobra virava a duzentos quilômetros por hora em volta do peito dele, o Gordo abriu o olho e só viu vento.

[...]

A sucuri desesperava, estava como a Fedra, do amor com todos os furores, aumentou a força do apertão para o máximo, a velocidade do gira-gira cresceu para quinhentos por hora, o vento levantava loucamente a folharada do chão, não houve jeito, como uma hélice dessas de brinquedo, que a gente puxa um elástico, a sucuri subiu, girando, girando, alcançou oito- 
centos metros de altura, um gavião amazônico catou-a nas garras e levou para o ninho (p. 91).

Sigmund Freud (1969, p. 38) afirma que o riso é o princípio do prazer, prazer provocado pela eliminação temporária da censura e da coerção, ao agir sobre as leis das sensações do inconsciente e não sobre as leis da razão. Em seu estudo sobre os chistes, o psicanalista se vale das técnicas de condensação e de deslocamento para a construção do riso. A primeira pode ser representada pela ambigüidade, em que o riso será provocado porque uma mesma expressão pode ser usada com duplo sentido. A segunda, do deslocamento, pode ser exemplificada, na maioria das vezes, pelas interpretações diferentes que as personagens fazem de determinado assunto ou contexto.

Hugo Ciência que estava mordido para mostrar o seu QI, falou:

- Do ponto de vista ecológico há vantagens evidentes de viver aqui. Ar puro, água pura do poço artesiano, comidas sem misturas químicas. Em São Paulo, se querem dar sabor de baunilha a seu sorvete eles põem piperonal, que é também usado para matar insetos. Se querem dar sabor de abacaxi, colocam ácido de etila, que é um solvente plástico que atinge pulmões e fígado. Em geléias e sucos de fruta, lá em São Paulo, usa-se o polivinilpirrolidone - P.V.P. - que é um veneno, mas dá sabor à geléia e ao suco. $\mathrm{O}$ boi é engordado artificialmente com hormônio que faz homem virar mulher e mulher virar homem. Em resumo, eu diria...

- Ainda bem - interrompeu o Gordo. - Isso me deixa aliviado.

- De estar aqui?

- Não, quando eu voltar para São Paulo posso continuar a comer oito bifes por refeição. No número par eu sempre viro homem de novo (p. 48).

Nesse excerto, vamos encontrar a segunda técnica, cujo resultado é o riso provocado pelo deslocamento que ocorre entre um comentário e uma réplica que prossegue o curso do pensamento de maneira distinta do comentário inicial. A idéia apresentada por Hugo Ciência - a química usada nos alimentos e que faz homem virar mulher e vice-versa - é interceptada pelo Gordo que a desloca para o fato de continuar a comer número par, pois desta maneira ele sempre voltará a ser homem. Pelo deslocamento ocorrido, todos sorriem com a graça do Gordo, menos Hugo Ciência que, apesar dos seus 250 pontos de QI, suou e não soube o que dizer. 


\section{INTUIÇÃO, DIDATISMO E MORALISMO DILUÍDOS}

Em Sangue fresco, detectamos a transgressão de estereótipos e de valores cristalizados por meio das personagens femininas, como vimos no episódio das mães, no tópico anterior. Agora, veremos como João Carlos Marinho consegue diluir a intuição, o didatismo e o moralismo, de modo semelhante. Além disso, à maneira de Monteiro Lobato, o autor de Sangue fresco sabe ironizar, com humor e irreverência, o gênero policial, deixando espaços abertos ao riso, à magia, ao mistério e ao encantamento, que são o grande desafio do autor, seja ele de textos infantis, juvenis ou adultos.

É curioso observar que o perfil da mulher nos romances de suspense geralmente traz o estereótipo da intuição voltado para o bem, mas na obra de Marinho há uma transgressão desse modelo. Por exemplo, temos Berenice, garota decidida e de idéias e ações independentes. Ela troca de namorado sem sentir-se ameaçada ou arrependida; fala de gravidez com naturalidade não normal para uma criança de idade entre 9 e 11 anos.

Berenice participa de outras histórias de João Carlos Marinho, inclusive cedendo seu nome a três edições: O livro da Berenice, Berenice Detetive e Berenice contra o maníaco Janeloso. Também podemos observar como a personagem evolui. Em $O$ Gênio do crime, a participação de Berenice se restringe a algumas cenas na escola e nos pensamentos de Bolachão, ao passo que, em Sangue fresco, ela compartilha tanto das cenas de perigo quanto das de humor e diversão. Vejamos o comportamento de Berenice em relação ao Gordo. Eles namoram, mas, quando Berenice decide trocar de amor, nada a segura:

- Você devia ter mais responsabilidade - disse a Mariazinha. - Coitado do Gordo, matam o cachorro dele, a sucuri corre atrás dele, e agora você, de novo...

Berenice pôs a mão no queixo e falou:

- Você já viu uma corrente marítima: A gente quer nadar para lá, a corrente puxa para cá, a gente faz força para nadar para lá, a corrente continua puxando para cá, e vamos indo para dentro do redemoinho (p. 58).

Podemos estabelecer uma analogia entre Berenice e a boneca Emília, de Monteiro Lobato. Tal como a Emília, que se aproveitava do Visconde de Sabugosa para realizar seus intentos, Berenice se aproveita de Hugo Ciência para ajudá-la a namorar: 
- Então eu vou andando com o Alcides na frente e você (Hugo Ciência) vai atrás recitando poesia. Precisa declamar com emoção, com ritmo.

-Tá.

A Berenice, de mão dada com o Alcides, foi para o lado do pomar. Hugo Ciência vinha atrás, recitando (p. 59).

Ou para escrever um livro:

[...] - Como é que você pode escrever se não temos caneta nem papel?

- Eu dito para o Hugo Ciência. A memória dele não esquece.

- Conta um pouco - pediu Pituca.

- Fala pra eles, Hugo - disse a Berenice.

[...] Paixão Amazônica, por Anastácia Palova, primeira edição.

- Essa é a capa - falou Berenice - Tem uma fotografia minha, com uma onça no colo, meu cabelo liso caindo na boca dela (p. 102).

Esse excerto, além de representar a linguagem como auto-expressão, é análogo ao início de "Memórias da Emília" (Lobato, 1985), quando esta obriga o Visconde a "ajudá-la" a escrever suas memórias. Por sua vez, o capítulo em que se narra a aventura dos meninos no alto Amazonas pertence a Berenice, escrevendo, ou melhor, ditando um livro autobiográfico. Neste episódio de exercício metalingüístico, ela fala de amor, de gravidez, de "balançar a estrutura das mentalidades burguesas" e reforça sua participação (p. 105).

A professora Jandira é outra personagem que também mostra o outro lado da moeda. Mulher interesseira, a professora busca fama e dinheiro ao se relacionar com Ship O'Connors. Os interesses pessoais e financeiros falam mais alto nas personagens femininas, como demonstramos anteriormente. Vejamos como Jandira se torna senhora O'Connors:

- Tia - falou a Silvinha - você não acha enjoativo dormir com um velho feio?

- Quem ama o feio, bonito lhe parece - respondeu Jandira. - E o Shipinho é líder, tem magnetismo.

- Quando você dava aula para a gente já conhecia o Shipo? - perguntou Berenice.

- Não. Só conhecia a fama dele, as fotos nos jornais. Sexta-feira passada vi o Shipinho andando na rua Augusta, corri atrás dele, perguntei se queria casar comigo, ele me olhou e disse que sim (p. 67-68). 
Para Jandira, a fama de Ship é mais importante que a honestidade e outros atributos cristalizados como valores éticos e morais, a exemplo do bom caráter, da integridade e respeito a esses valores. Neste caso, há também alguma semelhança entre a professora Jandira e a boneca Emília, que se casa com Rabicó por interesse.

Podemos perceber a presença de Lobato na narrativa de João Carlos Marinho. Além disso, a presença de um moralismo e didatismo é sutilmente disfarçada. $\mathrm{O}$ moralismo em geral não é declarado, mas pode ser notado pelo comportamento do Gordo e das crianças protagonistas, cujos pais não apresentam vícios e estão muito ligados aos filhos.

Quando alguém precisa de ajuda, esta não é negada, mesmo no caso de Alcides, garoto maltratado pela própria família e que não quer voltar para casa. Por esse motivo, ele delata o grupo para Ship, traindo a confiança de todos, mas se arrepende e tenta suicídio. Edmundo fica com pena e oferece sua casa para Alcides morar quando eles conseguirem se livrar do malfeitor. A punição de Ship e a premiação dos meninos com muita comida e a presença simpática de Frade João também podem ser encaradas como um tipo de moralismo.

Quanto ao didatismo, o autor o dilui e faz isso por meio de várias personagens como Hugo Ciência e o Gordo. Assim como a perspicácia e ousadia do Gordo, o saber de Hugo é necessário para que o grupo não se perca e consiga enfrentar os perigos. Como nos contos de fadas, em Sangue fresco há uma mensagem direcionada ao leitor, mas, graças à intervenção de outras instâncias narrativas ligadas ao eixo da aventura em plena selva, a história tende a abandonar o discurso utilitário e a adotar o discurso estético.

\section{INTERTEXTUALIDADE: AS VOZES PRESENTES EM SANGUE FRESCO}

Marcando a presença de outros escritores, o tema da intertextualidade está presente em Sangue fresco. Julgamos pertinente enfocá-lo por destacar o importante papel do escritor no despertar de uma consciência crítica. Nessa novela, a intertextualidade acontece por meio das vozes do narrador ou das personagens, reiterando a influência de grandes escritores como Monteiro Lobato para as gerações vindouras. Autores, como Ana Maria Machado, Ruth Rocha e outros, não negam a influência do criador de Emília. Inclusive em Sangue fresco, ele está presente nos intertextos e nas entrelinhas do discurso de Berenice. 
Com relação à história, esta se constrói entremeando vários discursos - voz do narrador e voz das personagens - com recurso a certo humor que quebra a dramaticidade do narrado. A voz do narrador ajuda a montar o cenário, dando-nos noções de espaço e tempo, ao passo que a voz das personagens constrói a fabulação.

$\mathrm{Na}$ página 70, neste artigo, no excerto em que a sucuri tenta agarrar o Gordo quando ele estava todo ensaboado, temos o intertexto com a música "Amada-amante", de Roberto Carlos, e com Fedra, personagem da mitologia grega. Aliás, é interessante e muito engenhoso como João Carlos Marinho faz o resgate da história de Fedra no episódio do desejo da sucuri pelo Gordo. Para quem não conhece, Fedra casa-se com Teseu, o herói que venceu o Minotauro, mas apaixona-se loucamente por Hipólito, seu enteado, e tenta seduzi-lo repetidas vezes. Isto aconteceu porque Afrodite, atraída pela beleza de Hipólito e enciumada pela devoção do rapaz a Ártemis, promete destruí-lo. Contam que Afrodite enfeitiça Fedra que se apaixona por Hipólito. Enquanto o rapaz a rejeitava, Fedra continuava a solicitar as afeiçóes dele, numa louca insistência que resulta em desespero (Bierlein, 2004, p. 204). Assim, Fedra tem um final infeliz, pois se enforca. A sucuri também tem um final infeliz ao ser levada por um gavião amazônico.

Turchi (1995, p. 138) confirma esse procedimento ao declarar que "a paródia aos romances policiais se dá, também, através dos jogos intertextuais comuns desde os romances clássicos de enigma”. Esta reflexão nos leva ao trabalho de Bakhtin (1999), teórico da literatura do nosso século que realizou estudo sobre as principais formas de expressão das manifestações da cultura cômica popular da Idade Média e do Renascimento. O teórico afirma que várias paródias latinas dessa época realizaram a degradação do sublime ao levarem a comicidade para textos bíblicos ou sagrados.

No entanto, a paródia moderna não conserva a mesma carga de degradação e ambivalência da paródia original. Como exemplo da forma de degradação a que Bakhtin se refere, temos o grande apetite de Frade João e o uso de citações bíblicas, como neste trecho: "Pá Pá Pá - disse o frade. - Nem todos os bandidos do mundo me fariam adiar um bom almoço. Dai de comer a quem tem fome, dizem as escrituras, eu sou homem de fé, obedeço ao mandamento, cada vez que tenho fome eu dou-me de comer" (p. 118). A caracterização hiperbólica da gula do Gordo e do apetite de Frade João beira o exagero e o ridículo, próprios da caricatura, reforçada pela linguagem e pelo humor: "Mais frango, cozinheiro! - gritou frade João - Mais frango e mais vinho! Esses bandidos quase nos fazem perder a 
paciência, não é, Gordo? O Gordo deu uma garfada e falou: - A paciência sim, mas não o apetite" (p.123). O elemento intensificador do humor está presente na oralidade, que aproxima mais a narrativa do leitor, no uso de gírias e no tom bem humorado, que confere velocidade ao ritmo cênico, promovendo o riso.

De fato, em Sangue fresco o suspense cede lugar ao ridículo e a tensão é substituída pelo humor. Talvez sejam estes dois elementos que mais aproximam Sangue fresco da paródia. Segundo Sant'Anna (1985, p. 12), o dicionário de Brewer enfatiza uma definição curta e funcional sobre o termo paródia: "significa uma ode que perverte o sentido de outra ode (grego: para-ode)". Mas, ainda de acordo com Sant'Anna, modernamente, a paródia se define através de um jogo intertextual.

A paródia, grosso modo, seria como um efeito metalingüístico, no qual a linguagem fala de outra linguagem. Em Sangue fresco, há exemplos de textos de Bilac, de Shakespeare e tragédia grega, no caso de Fedra, citado anteriormente. Vejamos como Marinho faz recortes de algumas poesias como as de Olavo Bilac: "Vejo-te bela, estátua da loucura/ Erguendo no ar a mão nervosa e fina". O verso de Bilac é recitado por Hugo Ciência para fazer um galanteio à beleza de Berenice. Não podia ser mais apropriado.

Como sempre, cabe a Hugo Ciência recitar e lembrar grandes poetas. Ao nomear o barco com o qual os protagonistas fugiriam de Ship O'Connors, Marinho trabalha sutilmente a apresentação de Shakespeare para o leitor:

- É preciso dar um nome ao barco - falou Berenice. - Eu não ando em barco sem nome. Hugo Ciência, que estava de ótimo humor, ajoelhou-se aos pés dela, abriu os braços e declamou Shakespeare:

"Que há num simples nome?

O que chamamos rosa

Sob outra designação

Teria igual perfume."

Está bem disse a Berenice, dando risada e mostrando os belos dentes. Em homenagem a seu poema o barco vai chamar Julieta (Referência a Romeu e Julieta, p. 98-99).

Já havíamos comentado a semelhança de Berenice com Emília, a boneca de pano, mas há, também, outra referência a Monteiro Lobato. Vejamos este intertexto com outra personagem Lobatiana: "Interessante o 
Gordo de cócora - falou Pituca. - Parece o Jeca Tatu” (p. 78). São recorrentes, na obra de João Carlos Marinho, referências ao criador da boneca Emília. No livro O gênio do crime, Edmundo, Pituca e Gordo vão conversar sobre a melhor estratégia para seguir o cambista no Largo de São Bento e o Gordo começa a falar sem parar e Edmundo diz o seguinte: "- Chega! Parece que o Gordo engoliu a pílula do doutor caramujo, passou de mudo a falante". Quem conhece o episódio do doutor caramujo a quem Emília chamará de doutor cara de coruja compreenderá perfeitamente do que Edmundo está falando (Marinho, 1969, p. 33).

A presença de outros escritores nas narrativas de Sangue fresco abre espaço para a inserção de João Carlos Marinho como leitor, ou seja, a gênese do texto se comprometendo com outros textos da tradição. Essa presença marca a multiplicidade de vozes no texto, não só recolhendo a voz social ou individual recalcada, na perspectiva de Bakhtin, mas também na instauração de uma linguagem que controla o seu próprio domínio no momento de encontro com o leitor que, para usufruir do texto, deverá ter o que Umberto Eco (1986) denomina de competência intertextual. O texto literário, então, se torna crítico de si mesmo, evidenciando com mais clareza a consciência criadora.

\section{REFERÊNCIAS}

BAKHTIN, M. A cultura popular na Idade Média e no Renascimento: o contexto de François Rabelais. Tradução de Yara Frateschi Vieira. São Paulo: Hucitec; Brasília: Editora da Universidade de Brasília, 1999.

BIERLEIN, J. F. Mitos paralelos. Tradução de Pedro Ribeiro. Rio de Janeiro: Ediouro, 2004.

FREUD, S. Os chistes e sua relação com o inconsciente. Rio de Janeiro: Imago, 1969. p. 30-72.

ECO, U. O leitor-modelo. In: __. Lector in fabula. Tradução de Attílio Cancian. São Paulo: Perspectiva, 1986. Cap. 1.

LAJOLO, M.; ZILBERMAN, R. Literatura infantil brasileira: história \& histórias. 2. ed. São Paulo: Ática, 1985.

LOBATO, M. Memórias da Emília. In: __. Caçadas de Pedrinho. $O$

Saci. Memória de Emília. São Paulo: Brasiliense, 1985. p. 239-292. 
MARINHO, J. C. O gênio do crime. São Paulo: Global, 1969. . O caneco de Prata. São Paulo: Global, 1971. . Sangue fresco. 6. ed. São Paulo: Global, 1986.

SANT’ANNA, A. R. de. Paródia, paráfrase \& cia. São Paulo: Ática, 1985.

SILVA, V. M. T. Narrativas de suspense. In: MELLO, A. M. L. et al. Literatura infanto-juvenil: prosa \& poesia. Goiânia: UFG, 1995. p. 107-122.

TODOROV, T. Tipologia do romance policial. In: As estruturas narrativas. Tradução de Leyla Perrone-Moisés. 2. ed. São Paulo: Perspectiva, 1970. p. 93-104.

TURCHI, M. Z. Gênio do crime: do suspense à crítica social. In: MELLO, A. M. L. et al. Literatura infanto-juvenil: prosa \& poesia. Goiânia: UFG, 1995. p. 123-142.

Recebido em: 18 nov. 2005 Aceito em: 23 fev. 2006 